\section{Exploring the Impact of Drug Use on Aggression and Delinquency Among Adults}

\section{Fakiha Shabbir*, Muhammad Bilal Javaid, Muhammad Aaqib and Syed Haider Ali Rizvi}

Department of Psychology, International Islamic University, Islamabad, Pakistan

\begin{abstract}
Aim: The purpose of present study was to find relationship between aggression and delinquency and to investigate moderating role of drug use between aggression and delinquency among adults.
\end{abstract}

Sample and methods: Convenient sampling was used to select research sample consisting $(\mathrm{N}=300)$ adult males. Participants of study included 150 drug users and 150 non drug users, selected from different areas of Islamabad and Rawalpindi including rehabilitation centers, psychological clinics and few offices. The age of participants ranged from 25-35 years. Informed consent was taken from participants before filling the questionnaires. The research protocols were administered to participants along with verbal instructions. They included demographic sheet, Aggression Scale, Self-Reported Delinquency Scale and Drug Abuse Screening Test (DAST-10). The data from this method was tabulated to conclude the results of research using SPSS software. Reliability analysis, Correlation, $t$ test and regression analysis were used to test hypotheses of the study. Data was statistically analyzed by statistical package for social sciences (SPSS23 V).

Results and conclusion: The results showed that aggression and delinquency were positively correlated with each other whereas delinquency was positively correlated with drug use. Aggression also had a positive relation with drug use. These findings are in line with previous research findings. Results further explained that drug use act as a moderator among aggression and delinquency

*Corresponding author: Fakiha Shabbir, Department of Psychology, International Islamic University, Islamabad, Pakistan, E-mail: psychservices786@gmail. com

Citation: Shabbir F, Javaid MB, Aaqib M, Rizvi SHA (2020) Exploring the Impact of Drug Use on Aggression and Delinquency Among Adults. J Addict Addictv Disord 7: 51

Received: August 06, 2020; Accepted: August 27, 2020; Published: September 07,2020

Copyright: (c) 2020 Shabbir F, et al. This is an open-access article distributed under the terms of the Creative Commons Attribution License, which permits unrestricted use, distribution, and reproduction in any medium, provided the original author and source are credited. for male adults. Moreover, the results indicated that drug users have significantly high rates of aggression as compared to drug non-users. Similarly, drug users are higher in delinquency as compared to drug non-users.

Suggestion: The sample of the study was selected only from Islamabad and Rawalpindi. For future studies, corporate evaluations among several cities can be conducted with a good sample size.

Keywords: Adults; Aggression; Delinquency; Drug use

\section{Introduction}

\section{Aggression}

Aggression is defined as behavior that creates tender and painful experience to others or as acts that are vicious to one's self, others or things [1]. Aggression is noticeable behavior which can collapse, hurt, threaten or impair a person or destroy an object. It is not planned occurring majorly during times of stress, fatigue or frustration. Aggression is any behavior that delivers on noxious stimulus to another person [2]. Aggression is any act that is planned to injure the target. A general definition of aggression is a behavioral act that could hurt or harm to another person [3].

It is difficult to define aggression, as people use this term to explain a large variety of actions, for example, to hurt others, forceful dealing with others, assertiveness etc. Aggressive behavior towards nonliving objects is the outcome of frustration [4]. Aggression is any kind of act planned to harm or hurt other person and the victim avoid those actions targeted toward him. The behaviors or actions that cause bodily or physical injury to others are aggressive acts of aggression. Human intensions behind are complex to understand. Aggressive acts produce noxious stimulus to another organism and emphasis is on the consequences of the aggressive acts rather than the intensions [2]. Breakwell [5], stated that people commit aggression with ease but find the term too complex to define for all fields of study. Aggression has been divided into four elements that are verbal aggression, physical aggression, anger and hostility. Anger is thought to be the link between all other elements. As aggression is associated with strong negative emotional state of anger so it serves as a prime condition that leads aggressive behavior [2].

\section{Delinquency}

Conduct that is out of accord with accepted behavior or the law; especially juvenile is called delinquency [6]. Delinquency implies conduct that does not conform to the legal or moral standards of society; it usually applies only to acts that, if performed by an adult, would be termed criminal. It is thus distinguished from a status offense, a term applied in the United States and other national legal systems to acts considered wrongful when committed by a juvenile but not when committed by an adult [7]. 
Most delinquents do not continue this behavior into their adult life, for, as the circumstances of their lives change and they get a job, marry, or simply mature out of their turbulent adolescence, their conduct usually falls in line with societal standards. Although the evidence is ambiguous, most delinquents adjust to a noncriminal life, yet the proportion of delinquents who become criminals is higher than that of non-delinquents. In recent years' a higher proportion of youth have experienced arrests by their early 20 s than in the past, although some scholars have concluded this may reflect more aggressive criminal justice and zero-tolerance policies rather than changes in youth behavior. Juvenile crimes can range from status offenses (such as underage smoking), to property crimes and violent crimes. Youth violence rates in the United States have dropped to approximately $12 \%$ of peak rates in 1993 according to official US government statistics, suggesting that most juvenile offending is non-violent [7].

\section{Drug use}

Many people may repeatedly use a drug, though their routine work, social and family responsibilities are severely disturbed. The significant loss caused by the continuous use of an activity or drugs is the disturbance or impairment of social life. The pathological set of behavior related to the use of drugs, is the key for diagnosing substance based disorders. All these pathological set of behavior are categorized into four main groups (DSM-V, 2013). They may show poor school performances and even fail to work, unable to look after family and fulfill social liabilities. When a particular drug is continuously use despite of its problems is also come in addiction. Such problems may be interpersonal problem like arguing with other members of the family about the addiction and even may cut off with friends and colleagues due to repeated drug use. Addiction also causes the loss of recreational activities and social activities. The addictive people may give less time to family and friends/colleagues.

The main problem of this criterion is the inability of a person to abstain from using the harmful drugs. The use of drugs like using alcohol during driving a vehicle or running any other machines also the case of addiction because such activity may cause serious damage if not done carefully. May people consume drugs even when the consequences of use are obvious to them. For instance a person continues to smoke a cigarette or drinking alcohol despite of suffering from lung and liver diseases.

West [8], reviewed about thirty theories concerning drug use and addiction for psychological point of view. One of the common theories is self-medication theory related to the use of drug use in adult persons. The theory has a potential to explain the association between drug use and mental and health issues. The theory described that most of the adult people uses drugs to get relief and pleasant sensation to avoid uneasy and stress condition. The people are more vulnerable to drug usage because they are unable to with stand the negative effects of the drug. Moreover the adult gain the ideas of using drugs from their friends, parents and colleagues. One of the examples of such theories is social cognitive learning [9] and the social development model [10].

Furthermore some other theories developed from both pharmacological and psychological studies which explain the rewarding effects of drugs and increasing the risks of addiction and dependence. For instance, the dopamine theory of drug reward describes the difference in the sensitivity of people to positive rewarding of drugs effect because every person has variable number of dopamine receptors on nerve cells. The theory also stated that the differential response of individual towards a drug used is associated with inheritance and genetic predisposition of the person [11].

According to the report of United Nations Office on Drugs and Crime [12], 6.0 percent of the population, or 6.7 million people, in Pakistan aged between 15 and 64 used drugs in the last 12 months. One in five used more than one substance. Over 4 million people using different substances in Pakistan are considered to be suffering from drug use disorders or are dependent requiring some form of intervention to address their drug use. On the other hand, the national capacity to provide treatment is limited to no more than 30,000 slots annually. Also many problem drug users expressed the desire but could not access or afford treatment. This gap in unmet need for treatment interventions at different levels would need to be addressed as a priority.

\section{Methods}

\section{Problem statement}

The present study aimed to find the relationship between aggression and delinquency as well as to investigate the moderating role of drug use between aggression and delinquency among adults.

\section{Objectives}

1. To find out the relationship between aggression and delinquency among adults.

2. To explore moderating effect of drug use on aggression and delinquency among adults.

3. To investigate differences in rates of aggression and delinquency among adults on the basis of drug use.

\section{Hypotheses}

1. Following hypotheses are formulated to achieve the objectives of the study;

2. There will be significant positive relationship between aggression and delinquency among adults.

3. Drug use will act as a moderator between aggression and delinquency among adults.

4. There will be differences in rates of aggression and delinquency among drug user and non-user adults.

\section{Sample}

Convenient sampling was used for the selection of the research sample. The sample of this study consisted of $(\mathrm{N}=300)$ adult males. Participants of this study included 150 drug users and 150 non drug users, who were selected from different areas of Islamabad and Rawalpindi including rehabilitation centers, psychological clinics and few offices. The age of participants ranged from 25-35 years.

\section{Procedure}

Informed consent was taken from the participants before filling the questionnaires. The research protocols were administered to the participants along with verbal instructions. They included demographic sheet, Aggression Scale, Self-Reported Delinquency 
Scale and Drug Abuse Screening Test (DAST-10). The data from this method was tabulated to conclude the results of the research using SPSS software. Reliability analysis, Correlation, $t$ test and regression analysis were used to test hypotheses of the study. Data was statistically analyzed by statistical package for social sciences (SPSS23 V).

\section{Instruments}

Demographic sheet: Demographic sheet was formulated to access the name of the participant, age, gender and family system.

Aggression scale: The Aggression Scale includes 11 items and was developed by Orpinas and Frankowski [13]. The scale measures behaviors that may cause emotional or bodily injury to other students. Although the directions used in instrument do not specify the location of these acts but largely the scale taps aggression against other students. Questions are limited to explicit display of violent actions. Responses to each item range from 0 times through 6 or more times. Thus, the aggression score range between 0 and 66 points. The alpha reliability of scale was reported to be .88 .

Self-reported delinquency scale: Self-Reported Delinquency Scale developed by Naqvi and Kamal [6], will be used for present study. Responses will be acquired on five point rating format which are all positively stated. This scale measures Self Reported Delinquency on following dimension, theft measured by (items no 1,10,17,19); drug abuse measured by $(2,8,9)$; lying measured by item no $(20)$; non compliance measured by item no (22); police encounter measured by item (14\&25); violence related delinquency (extraversion, vandalism, aggression) measured by item no $(3,7,12,21,26,27)$; cheating and gambling by item no $(4,6,11,23,24)$; and sex related delinquency (harassment, homosexuality, heterosexuality) measured by item no $(5,13,15,15,16,18)$. Scoring criteria is $0=$ never, once $=1,2-4$ times $=2$, $5-10$ times $=3$ and 10 or more times $=4$. The possible score range is from $0-108$; where minimum score is 0 and maximum score can be 108. The reliability of the scale is reported to be .79 .

Drug abuse screening test: Drug Abuse Screening Test (DAST-10) is a 10-item self-report instrument that has been condensed from the 28 -item DAST. It was copyrighted in 1982 by Harvey Skinner, $\mathrm{PhD}$ and the Centre for Addiction and Mental Health. Toronto, Canada. The Drug Abuse Screen Test (DAST-10) was designed as an assessment tool for the systematic examination of the maladaptive use of prescription drugs (substances obtained only by the order of a legal medical professional), illegal drugs (substances deemed as harmful and usually subject to legal restriction), or over-the-counter drugs (medicine that can be bought without a prescription), that may lead to social, occupational, psychological, or physical problems for the individual. It can be used with adults and older youth. The DAST-10 yields a quantitative index of the degree of consequences related to drug abuse. The instrument takes approximately 5 minutes to administer and may be given in either a self-report or interview format. The DAST may be used in a variety of settings to provide a quick index of drug abuse problems. There is a scoring system or value (0-10) for the Drug Abuse Screening Test (DAST-10).

\section{Operational definition}

Aggression: The term aggression refers to number of components that lead to harmful consequences for others. These may include verbal physical and emotional anger towards others [14].
Delinquency: Conduct that is out of accord with accepted behavior or the law; especially juvenile delinquency. High score on Self-Reported Delinquency Scale [6], will indicate high delinquency and low score on the scale will indicate low delinquency among adults.

Drug use: Many people may repeatedly use a drug, though their routine work, social and family responsibilities are severely disturbed. The significant loss caused by the continuous use of an activity or drugs is the disturbance or impairment of social life. The pathological set of behavior related to the use of drugs, is the key for diagnosing substance based disorders. All these pathological set of behavior are categorized into four main groups (DSM-V, 2013).

\section{Results}

The present study aimed to find the relationship between aggression and delinquency as well as to investigate the moderating role of drug use between aggression and delinquency among adults. Aggression Scale was used to measure aggression, Self-Reported Delinquency Scale was used to access delinquency and Drug Abuse Screening Test (DAST-10) was used to explore drug use among adult sample. Reliability analysis, Correlation, t-test and regression analysis were used to test hypotheses of the study. Data was statistically analyzed by statistical package for social sciences (SPSS23 V).

Table 1 indicates the Cronbach's alpha reliability of Aggression Scale, Self-Reported Delinquency Scale and Drug Abuse Screening Test (DAST-10). It shows that all scales have high alpha reliability including Aggression Scale $(\alpha=0.78)$, Self-Reported Delinquency Scale $(\alpha=0.98)$ and Drug Abuse Screening Test $(\alpha=0.82)$ thus concluding that the data gathered by these instruments is reliable for data analysis.

\begin{tabular}{|c|c|c|c|c|c|}
\hline Variable & M & SD & a & Skewness & Kurtosis \\
\hline AG & 88.7 & 16.4 & 0.78 & 0.03 & -0.17 \\
\hline SRDC & 54.1 & 31.1 & 0.98 & -0.02 & -1.9 \\
\hline DAST & 10.0 & 3.5 & 0.82 & 0.12 & -1.3 \\
\hline
\end{tabular}

Table 1: Psychometric properties of Aggression Scale, Self-Reported Delinquency Scale and Drug Abuse Screening Test (DAST-10) $(\mathrm{N}=300)$.

Notes: $A G=$ Aggression Scale, $S R D C=$ Self-Reported Delinquency Scale, DAST $=$ Drug Abuse Screening Test.

Table 2 indicates correlation coefficients for Aggression Scale, Self-Reported Delinquency Scale and Drug Abuse Screening Test (DAST-10). The results show that aggression and delinquency are positively correlated $(\alpha=0.79 * *, p<0.001)$ with each other whereas delinquency is positively correlated with drug use $\left(\alpha=0.73^{* *}\right.$, $\mathrm{p}<0.001)$. Aggression also has a positive relation with drug use $\left(\alpha=0.65^{* *}, \mathrm{p}<0.001\right)$.

\begin{tabular}{|c|c|c|c|}
\hline Variables & $\mathbf{1}$ & $\mathbf{2}$ & $\mathbf{3}$ \\
\hline Aggression & 1 & $0.79^{* *}$ & $0.65^{* *}$ \\
\hline Delinquency & - & 1 & $0.73^{* *}$ \\
\hline Drug use & - & - & 1 \\
\hline
\end{tabular}

Table 2: Correlation matrix for Aggression Scale, Self-Reported Delinquency Scale and Drug Abuse Screening Test (DAST-10) $(\mathrm{N}=300)$.

Notes: $\mathrm{p}=<0.01 * *$ 
Table 3 illustrates moderation analysis to study the moderating effect of drug use between aggression and delinquency among adults. The table depicts that aggression $(\beta=0.14, \mathrm{p}<0.01)$ and drug use $(\beta=0.24, \mathrm{p}<0.01)$ are significant predictors of delinquency. The value of $\mathrm{R}^{2}$ shows that $60 \%$ of variance is accounted for delinquency by both aggression and drug use $(\beta=2.1, \mathrm{p}<0.01)$. The above stated prediction is significant at $\mathrm{F}(230.7)$ and $\mathrm{p}<0.01$.

\begin{tabular}{|c|c|c|}
\hline & \multicolumn{2}{|c|}{ Delinquency } \\
\hline & & Model 1 \\
\hline Variables & B & $95 \%$ CI \\
\hline Constant & 33.8 & {$[1.8,9.3]$} \\
\hline Aggression & & \\
\hline Drug use & 0.14 & \\
\hline 0.24 & {$[-1.4,1.7]$} & \\
\hline$[-1.6,1.8]$ & & \\
\hline Aggression*Drug use & 2.1 & {$[-2.2,2.7]$} \\
\hline $\mathrm{R}^{2}$ & \multicolumn{2}{|c|}{0.60} \\
$\mathrm{~F}$ & \multicolumn{2}{|c|}{230.7} \\
\hline
\end{tabular}

Table 3: Moderation Analysis of Drug Use for Aggression and Delinquency among adults $(\mathrm{N}=300)$.

Note: $\mathrm{CI}=$ Confidence Interval

Table 4 showed the results of t-test for comparing mean differences in rates of aggression and delinquency on the basis of drug use and no drug use among adults. Thus indicating that drug users $(\mathrm{M}=89.7$, $\mathrm{SD}=16.8$ ) have significantly high rates of aggression as compared to drug non-users $(M=80.7, S D=16.1)$. Similarly, drug users $(M=58.7$, $\mathrm{SD}=30.8)$ are higher in delinquency as compared to drug non-users $(\mathrm{M}=49.5, \mathrm{SD}=30.4)$.

\section{Discussion}

Present study was done to find the relationship between aggression and delinquency as well as to investigate the moderating role of drug use between aggression and delinquency among adults. A general definition of aggression is a behavioral act that could hurt or harm to another person [3]. Aggression has been divided into four elements that are verbal aggression, physical aggression, anger and hostility. Anger is thought to be the link between all other elements. As aggression is associated with strong negative emotional state of anger so it serves as a prime condition that leads aggressive behavior [2]. Delinquency implies conduct that does not conform to the legal or moral standards of society; it usually applies only to acts that, if performed by an adult, would be termed criminal. It is thus distinguished from a status offense, a term applied in the United States and other national legal systems to acts considered wrongful when committed by a juvenile but not when committed by an adult [7]. Many people may repeatedly use a drug, though their routine work, social and family responsibilities are severely disturbed. The significant loss caused by the continuous use of an activity or drugs is the disturbance or impairment of social life. The pathological set of behavior related to the use of drugs, is the key for diagnosing substance based disorders. All these pathological set of behavior are categorized into four main groups (DSM-V, 2013). When a particular drug is continuously use despite of its problems is also come in addiction. Such problems may be interpersonal problem like arguing with other members of the family about the addiction and even may cut off with friends and colleagues due to repeated drug use.

Convenient sampling was used for the selection of the research sample. The sample of this study consisted of $(\mathrm{N}=300)$ adult males. Participants of this study included 150 drug users and 150 non drug users, who were selected from different areas of Islamabad and Rawalpindi including rehabilitation centers, psychological clinics and few offices. The age of participants ranged from 2535 years. Informed consent was taken from the participants before filling the questionnaires. The research protocols were administered to the participants along with verbal instructions. They included demographic sheet, Aggression Scale, Self-Reported Delinquency Scale and Drug Abuse Screening Test (DAST-10).

Table 1 indicated the Cronbach's alpha reliability of Aggression Scale, Self-Reported Delinquency Scale and Drug Abuse Screening Test (DAST-10). It showed that all scales had high alpha reliability including Aggression Scale $(\alpha=0.78)$, Self-Reported Delinquency Scale $(\alpha=0.98)$ and Drug Abuse Screening Test $(\alpha=0.82)$ thus concluded that the data gathered by these instruments was reliable for data analysis.

The first hypothesis proposed that there will be significant positive relationship between aggression and delinquency among adults. Table 2 demonstrated correlation coefficients for Aggression Scale, Self-Reported Delinquency Scale and Drug Abuse Screening Test (DAST-10). The results showed that aggression and delinquency were positively correlated $\left(\alpha=0.79^{* *}, \mathrm{p}<0.001\right)$ with each other whereas delinquency was positively correlated with drug use $\left(\alpha=0.73^{* *}\right.$, $\mathrm{p}<0.001)$. Aggression also had a positive relation with drug use $\left(\alpha=0.65^{* *}, p<0.001\right)$. These findings are in line with previous research findings.

In a previous study with the sample of 206 male adolescents of Karachi, mean difference suggest that delinquent adolescents have high levels of aggression as compared to their non-delinquent counterparts [15]. Thus delinquent adolescents who are deprived of a salubrious environment and who are raised in crime stricken neighborhoods are more vulnerable to develop aggression in early years of life and ultimately engage in delinquent and anti-social behaviors [16].

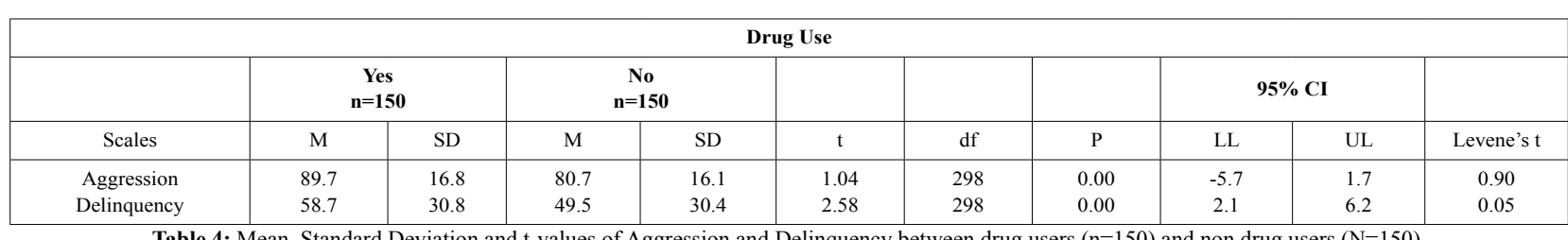

Table 4: Mean, Standard Deviation and t-values of Aggression and Delinquency between drug users $(\mathrm{n}=150)$ and non drug users $(\mathrm{N}=150)$. 
Aggressive adolescents are likely to engage in drug abuse because they are usually rejected by their peers and thus are more vulnerable to get entrapped in bad company where drug use is encouraged and facilitated. Affiliation with a deviant peer group is also indicative of social skill deficits (e.g. being impolite, uncompromising or indifferent) which makes it difficult for these individuals to engage in healthy social activities. Thus bad company might lead to delinquent acts and substance use.

Second hypothesis profess that Drug use will act as a moderator between aggression and delinquency among adults. Table 3 illustrated moderation analysis to study the moderating effect of drug use between aggression and delinquency among adults. The table depicted that aggression $(\beta=0.14, p<0.01)$ and drug use $(\beta=0.24$, $\mathrm{p}<0.01$ ) were significant predictors of delinquency. The value of $\mathrm{R}^{2}$ showed that $60 \%$ of variance was accounted for delinquency by both aggression and drug use $(\beta=2.1, \mathrm{p}<0.01)$. The above stated prediction was significant at $F(230.7)$ and $p<0.01$. These findings are in line with previous research findings.

There is evidence in literature which suggests that those who are aggressive and exhibit violent behaviour at a young age are more likely to succumb to substance abuse. Bukstein asserted that aggression in early life is a risk factor for the subsequent development of drug abuse. He also suggested that aggression gives an impact on progression of drug abuse because of its direct pharmacological effect or indirectly by its influence on attitude of the individual. Delinquents and those who engage in anti-social practices are most despised and are a neglected segment of Pakistani society. They are ostracized and alienated because of their anti-social behaviours which as an effect fortify their resentment toward society and increase their likelihood to join delinquent peer groups.

Third hypothesis proposed that there will be differences in rates of aggression and delinquency among drug user and non-user adults. Table 4 showed the results of t-test for comparing mean differences in rates of aggression and delinquency on the basis of drug use and no drug use among adults. Thus indicating that drug users $(\mathrm{M}=89.7$, $\mathrm{SD}=16.8$ ) have significantly high rates of aggression as compared to drug non-users $(\mathrm{M}=80.7, \mathrm{SD}=16.1)$. Similarly, drug users $(\mathrm{M}=58.7$, $\mathrm{SD}=30.8)$ are higher in delinquency as compared to drug non-users $(\mathrm{M}=49.5, \mathrm{SD}=30.4)$. These findings are in line with previous research findings.

In a previous study with the sample of 206 male adolescents of Karachi, mean difference suggest that those who use drugs have a high level of aggression than those who do not use drugs [15]. Therefore, we can aver that adolescents who use drugs are generally more aggressive and their aggression shoves them into situations where drug use is facilitated and encouraged. High level of aggression among drug users can be attributed to their excessive drug usage as mental inhibitions are set free under influence of drugs making individuals prone to aggressive behavior [17].

Past literature also confirms that frequent use and abuse of drugs is linked with chronic delinquency and indulgence in antisocial acts [18]. There is an undeniable link between substance abuse and delinquency. Arrest, adjudication and intervention by the juvenile justice system are eventual consequences for many youth engaged in alcohol and other drug use. It cannot be claimed that substance abuse causes delinquent behavior or delinquency causes alcohol and other drug use. However, the two behaviors are strongly correlated and often bring about school and family problems, involvement with negative peer groups, a lack of neighborhood social controls and physical or sexual abuse [10].

\section{Conclusion}

Present study was carried out in order to find the relationship between aggression and delinquency as well as to investigate the moderating role of drug use between aggression and delinquency among adults. The results showed that aggression and delinquency were positively correlated with each other whereas delinquency was positively correlated with drug use. Aggression also had a positive relation with drug use. These findings are in line with previous research findings. Results further explained that drug use act as a moderator among aggression and delinquency for male adults. Moreover, the results indicated that drug users have significantly high rates of aggression as compared to drug non-users. Similarly, drug users are higher in delinquency as compared to drug non-users.

\section{Implications, Limitations and Suggestions}

- This study has offered some insights, guidelines and caveats for future research.

- This study is an effective contribution to the understanding of the adaptation of drug users as well as to study consequences of their drug use in certain perspectives of their lives.

- The sample taken in the study was taken only from Islamabad and Rawalpindi. For future studies, corporate evaluations among several cities can be conducted with a good sample size.

\section{References}

1. Connor DF, Carlson GA, Chang KD, Daniolos PT, Ferziger R, et al. (2006) Juvenile maladaptive aggression: A review of prevention, treatment, and service configuration and a proposed research agenda. J Clin Psychiatry 67: 808-820.

2. Buss AH, Perry MP (1992) The Aggression Questionnaire. J Pers Soc Psychol 63: 452-459.

3. Dodge KA, Lochman JE, Harnish JD, Bates JE, Pettit GS (1997) Reactive and proactive aggression in school children and psychiatrically impaired chronically assaultive youth. J Abnorm Psychol 106: 37-51.

4. Barr GA, Gibbons JL, Moyer KE (1976) Male-female differences and the influence of neonatal and adult testosterone on intraspecies aggression in rats. J Comp Physiol Psychol 90: 1169-1183.

5. Breakwell GM (1997) Coping with Aggressive Behavior. BPS Blackwell, Leicester, UK.

6. Naqvi I, Kamal A (2013) Personality traits predicting the delinquency among laborer adolescents. Journal of Social Sciences 7: 15-26.

7. Goode E (2011) Young killer, bad seed or work in progress. New York Times Goode, New York, USA.

8. West R (2006) Towards a comprehensive theory of addiction. Drugs and Alcohol Today 6: 28-32.

9. Bandura A (1986) A social cognitive theory of personality. In Pervin L, John O (eds.). Handbook of personality. Guilford Publications, New York, USA.

10. Hawkins JD, Catalano RF (1992) The social development model: A theory of antisocial behavior. Cambridge University Press, Cambridge, UK. 
11. Volkow ND, Fowler JS, Wang GJ, Baler R, Telang F (2009) Imaging dopamine's role in drug abuse and addiction. Neuropharmacology 56: 3-8.

12. United Nations Office on Drugs and Crime (2013) Narcotics Control Division, Government of Pakistan, Pakistan.

13. American Psychiatric Association (2013) The Diagnostic and Statistical Manual of Mental Disorders (DSM-5 ${ }^{\circledR}$ ). American Psychiatric Association, Philadelphia, USA.

14. Orpinas P, Frankowski R (2001) The Aggression Scale: A self-report measure of aggressive behavior for young adolescents. The Journal of Early Adolescence 21: 50-67.

15. Shahzad S, Yasmin S (2012) Aggression as risk for delinquency and substance abuse in adolescents. International Journal of Prevention and Treatment of Substance Use Disorders 7: 363-371.
16. Moffitt TE (1993) Adolescence-limited and life-course-persistent antisocial behavior: A developmental taxonomy. Psychological Review 100: 674-701.

17. O’Donnell J, Hawkins JD, Abbott RD (1995) Predicting serious delinquency and substance use among aggressive boys. J Consult Clin Psychol 63: 529-537.

18. Hawkins JD, Jenson JM, Catalano RF, Lishner DM (1988) Delinquency and drug abuse: Implications for social services. Social Service Review 62: $258-284$ 


\section{If}

Advances In Industrial Biotechnology | ISSN: 2639-5665

Advances In Microbiology Research | ISSN: 2689-694X

Archives Of Surgery And Surgical Education | ISSN: 2689-3126

Archives Of Urology

Archives Of Zoological Studies | ISSN: 2640-7779

Current Trends Medical And Biological Engineering

International Journal Of Case Reports And Therapeutic Studies | ISSN: 2689-310X

Journal Of Addiction \& Addictive Disorders | ISSN: 2578-7276

Journal Of Agronomy \& Agricultural Science | ISSN: 2689-8292

Journal Of AIDS Clinical Research \& STDs | ISSN: 2572-7370

Journal Of Alcoholism Drug Abuse \& Substance Dependence | ISSN: 2572-9594

Journal Of Allergy Disorders \& Therapy | ISSN: 2470-749X

Journal Of Alternative Complementary \& Integrative Medicine | ISSN: 2470-7562

Journal Of Alzheimers \& Neurodegenerative Diseases | ISSN: 2572-9608

Journal Of Anesthesia \& Clinical Care | ISSN: 2378-8879

Journal Of Angiology \& Vascular Surgery | ISSN: 2572-7397

Journal Of Animal Research \& Veterinary Science | ISSN: 2639-3751

Journal Of Aquaculture \& Fisheries | ISSN: 2576-5523

Journal Of Atmospheric \& Earth Sciences | ISSN: 2689-8780

Journal Of Biotech Research \& Biochemistry

Journal Of Brain \& Neuroscience Research

Journal Of Cancer Biology \& Treatment | ISSN: 2470-7546

Journal Of Cardiology Study \& Research | ISSN: 2640-768X

Journal Of Cell Biology \& Cell Metabolism | ISSN: 2381-1943

Journal Of Clinical Dermatology \& Therapy | ISSN: 2378-8771

Journal Of Clinical Immunology \& Immunotherapy | ISSN: 2378-8844

Journal Of Clinical Studies \& Medical Case Reports | ISSN: 2378-8801

Journal Of Community Medicine \& Public Health Care | ISSN: 2381-1978

Journal Of Cytology \& Tissue Biology | ISSN: 2378-9107

Journal Of Dairy Research \& Technology | ISSN: 2688-9315

Journal Of Dentistry Oral Health \& Cosmesis | ISSN: 2473-6783

Journal Of Diabetes \& Metabolic Disorders | ISSN: 2381-201X

Journal Of Emergency Medicine Trauma \& Surgical Care | ISSN: 2378-8798

Journal Of Environmental Science Current Research | ISSN: 2643-5020

Journal Of Food Science \& Nutrition | ISSN: 2470-1076

Journal Of Forensic Legal \& Investigative Sciences | ISSN: 2473-733X

Journal Of Gastroenterology \& Hepatology Research | ISSN: 2574-2566
Journal Of Genetics \& Genomic Sciences | ISSN: 2574-2485

Journal Of Gerontology \& Geriatric Medicine | ISSN: 2381-8662

Journal Of Hematology Blood Transfusion \& Disorders | ISSN: 2572-2999

Journal Of Hospice \& Palliative Medical Care

Journal Of Human Endocrinology | ISSN: 2572-9640

Journal Of Infectious \& Non Infectious Diseases | ISSN: 2381-8654

Journal Of Internal Medicine \& Primary Healthcare | ISSN: 2574-2493

Journal Of Light \& Laser Current Trends

Journal Of Medicine Study \& Research | ISSN: 2639-5657

Journal Of Modern Chemical Sciences

Journal Of Nanotechnology Nanomedicine \& Nanobiotechnology | ISSN: 2381-2044

Journal Of Neonatology \& Clinical Pediatrics | ISSN: 2378-878X

Journal Of Nephrology \& Renal Therapy | ISSN: 2473-7313

Journal Of Non Invasive Vascular Investigation | ISSN: 2572-7400

Journal Of Nuclear Medicine Radiology \& Radiation Therapy | ISSN: 2572-7419

Journal Of Obesity \& Weight Loss | ISSN: 2473-7372

Journal Of Ophthalmology \& Clinical Research | ISSN: 2378-8887

Journal Of Orthopedic Research \& Physiotherapy | ISSN: 2381-2052

Journal Of Otolaryngology Head \& Neck Surgery | ISSN: 2573-010X

Journal Of Pathology Clinical \& Medical Research

Journal Of Pharmacology Pharmaceutics \& Pharmacovigilance | ISSN: 2639-5649

Journal Of Physical Medicine Rehabilitation \& Disabilities | ISSN: 2381-8670

Journal Of Plant Science Current Research | ISSN: 2639-3743

Journal Of Practical \& Professional Nursing | ISSN: 2639-5681

Journal Of Protein Research \& Bioinformatics

Journal Of Psychiatry Depression \& Anxiety | ISSN: 2573-0150

Journal Of Pulmonary Medicine \& Respiratory Research | ISSN: 2573-0177

Journal Of Reproductive Medicine Gynaecology \& Obstetrics | ISSN: 2574-2574

Journal Of Stem Cells Research Development \& Therapy | ISSN: 2381-2060

Journal Of Surgery Current Trends \& Innovations | ISSN: 2578-7284

Journal Of Toxicology Current Research | ISSN: 2639-3735

Journal Of Translational Science And Research

Journal Of Vaccines Research \& Vaccination | ISSN: 2573-0193

Journal Of Virology \& Antivirals

Sports Medicine And Injury Care Journal | ISSN: 2689-8829

Trends In Anatomy \& Physiology | ISSN: 2640-7752

Submit Your Manuscript: https://www.heraldopenaccess.us/submit-manuscript 